\title{
LETTER
}

\section{A prolonged ICU stay after interhospital transport?}

\author{
Joep M Droogh"1, Maurits H Renes', Jack JM Ligtenberg² and Jan G Zijlstra'
}

See related research by Barratt et al., http://ccforum.com/content/16/5/R179

Transport of critically ill patients can be complicated [1-3]. Barratt and colleagues studied patients transferred for nonclinical reasons to evaluate the consequences of transportation [4]. There was no difference in mortality but the ICU length of stay (LOS) increased by 3 days, which was explained as a negative impact of the transport on patient physiology. We disagree with this conclusion.

First, by including only transports to level 3 ICUs the received level of care for transported patients will increase, introducing a bias.

Second, the increase in LOS can be interpreted as a result of selection bias, because patients with a short expected LOS would often not be considered eligible for transport. Also, since there was no increase in mortality, which would have been expected with an increased LOS, we might be looking at a mortality reduction as a result of the transfer to a higher-level ICU.

Third, Barrett and colleagues suggest that deterioration of patient physiology during transport is probably responsible for the increase in LOS. However, the reported Intensive Care National Audit and Research Centre scores before and after transport (although not validated for sequential patient assessments) do not support this assumption.

Fourth, the method of transportation should have been included in this study. Specialised transport teams deliver patients with a better acute physiology compared with nonspecialised teams $[2,5]$, making a need for regaining physiological stability unlikely.

In conclusion, we congratulate Barratt and colleagues for their research. However, we think their conclusion is premature because multiple possible confounders were not taken into account.

\section{Abbreviations \\ LOS, length of stay.}

\section{Competing interests}

The authors declare that they have no competing interests.

\section{Author details}

'Department of Critical Care, University Medical Center Groningen, University of Groningen, Hanzeplein 1, P.O. Box 30.001, 9700 RB Groningen, the Netherlands. ${ }^{2}$ Department of Emergency Medicine, University Medical Center Groningen, University of Groningen, Hanzeplein 1, P.O. Box 30.001, 9700 RB Groningen, the Netherlands

\section{Published: 23 November 2012}

\section{References}

1. Ligtenberg JJM, Arnold LG, Stienstra Y, van der WerfTS, Meertens JHJM, Tulleken JE, Zijlstra JG: Quality of interhospital transport of critically ill patients: a prospective audit. Crit Care 2005, 9:R446-R451.

2. Wiegersma JS, Droogh JM, Zij|stra JG, Fokkema J, Ligtenberg JJ: Quality of interhospital transport of the critically ill: impact of a mobile intensive care unit with a specialized retrieval team. Crit Care 2011, 15:R75.

3. Droogh JM, Smit M, Hut J, de Vos R, Ligtenberg JJ, Zijlstra JG: Inter-hospital transport of critically ill patients; expect surprises. Crit Care 2012, 16:R26.

4. Barratt $\mathrm{H}$, Harrison DA, Rowan KM, Raine R: Effect of non-clinical interhospital critical care unit to unit transfer of critically ill patients: a propensity-matched cohort analysis. Crit Care 2012, 16:R179.

5. Bellingan G, Olivier T, Batson S, Webb A: Comparison of a specialist retrieval team with current United Kingdom practice for the transport of critically ill patients. Intensive Care Med 2000, 26:740-744.

doi:10.1186/cc11857

Cite this article as: Droogh JM, et al.: A prolonged ICU stay after interhospital transport? Critical Care 2012, 16:465.
*Correspondence: j.m.droogh@umcg.nl

'Department of Critical Care, University Medical Center Groningen, University of Groningen, Hanzeplein 1, P.O. Box 30.001, 9700 RB Groningen, the Netherlands Full list of author information is available at the end of the article 